\title{
Compulsory treatment and the problem of safety in psychiatric hospitals Victor Fukalov
}

\author{
Address: Psychiatric hospital with intensive supervision (Kaliningrad PBSTIN), Prigorodnaja Ul. 2, 238154 Chernyakhovsk, Russia (Russian \\ Federation) \\ from WPA Thematic Conference. Coercive Treatment in Psychiatry: A Comprehensive Review \\ Dresden, Germany. 6-8 June 2007 \\ Published: 19 December 2007 \\ BMC Psychiatry 2007, 7(SuppI I):PII doi:I0.II86/I47I-244X-7-SI-PI I
}

This abstract is available from: http://www.biomedcentral.com/I47I-244X/7/SI/PII

(c) 2007 Fukalov; licensee BioMed Central Ltd.

In the Russian Federation safety of patients, medical and attendant personnel in specialized psychiatric hospitals for compulsory treatment is an actual problem. The psychiatric care of the patients in these establishments demands specially organized constant and intensive supervision with observance of the raised security measures. Necessity of special security measures is dictated by clinical and social - psychological features of a contingent of patients. The majority of patients has three mental disorders: schizophrenia, intellectual disabilities, and organic mental disorders; further, they have committed crimes against lives and health of persons, and also sexual offenses because of their disorders. The clinical and socialpsychological characteristics demonstrate the special danger of these patients for the public and the validity of expert decisions and judgements for the choice of a kind of compulsory treatment. In patients with psychotic disorders the probability of repeated aggressive actions during the first period of stay in a hospital is high, and also of aggravations of the psychosis. In persons with personality disorders medical therapy is less effective, they hardly transfer the limited mode, save the hostile attitude to the personnel and often provoke dangerous conflicts. High "density" of accommodation of potentially dangerous patients creates a raised degree of risk for patients and the personnel and does not allow to provide safety of participants of medical processes only with the activities of medical workers. Specially prepared security being an important part in medical rehabilitation is necessary. It should be created under the decision of the state bodies of the Russian Federation and submitted to the administration of hospitals. 